\title{
A STUDY ON THE VOLTAMMETRIC BEHAVIOUR OF SILVER ON ELECTRODISPERSED PLATINUM ELECTRODES IN ACID SOLUTION
}

\author{
M. E. Martins, R. C. Salvarezza and A. J. Arvia \\ Instituto de Investigaciones Fisicoquimicas Teoricas y Aplicadas (INIFTA), Universidad Nacional de La \\ Plata, Sucursal 4, Casilla de Correo 16, (1900) La Plata, Argentina
}

(Received 8 November 1990; in revised form 14 January 1991)

\begin{abstract}
The early stages of Ag electrodeposition on columnar structured Pt electrodes was investigated in acid solutions covering the underpotential deposition (upd) and overpotential deposition (opd) ranges. Results show a remarkable dependence of the Ag growth mode on the electrode roughness and potential sweep rate. At high potential sweep rates and large substrate roughness factors a 3-D to 2-D rearrangement can be detected. This process appears to be also accompanied by a $\mathrm{Pt}-\mathrm{Ag}$ formation. For this type of electrode, both processes hinder the nucleation and growth of the 3-D Ag phase. Under certain conditions the complete Ag plating of the entire porous structure can be produced and the voltammetric behaviour of the system then approaches that observed for the $\mathrm{Ag} / \mathrm{Ag}^{+}$electrode reaction at an electrochemical thin layer cell.
\end{abstract}

Key words: metal electrodeposition, electrode roughness, growth modes, microcolumnar structured metal electrodes, porous structures.

\section{INTRODUCTION}

Platinum electrodes with a reproducible surface texture and a variable degree of surface roughness can be obtained in situ by electroreducing hydrous $\mathrm{Pt}$ oxide layers accumulated under a periodic perturbing potential routine in acid or alkaline solutions[1-3]. This type of platinum electrode (hereafter denoted as electrodispersed Pt electrodes, EDPtE), show electroreflectance[4], ellipsometric[5] and impedance[6] characteristics which are typical of rough metal surfaces. The structure of EDPtE as concluded from STM[7], STM-SEM[8] and ellipsometry[5] data, can be described as a columnar microstructure[ 7, similar to that found in metal deposition from vapour[9]. Furthermore, the EDPtEs exhibit specific electrocatalytic properties for several reactions $[10,11]$.

The $\mathrm{Ag} / \mathrm{Ag}^{+}$electrode reactions have been extensively investigated both in the underpotential (upd) and the overpotential (opd) ranges by using polycrystalline mirror polished $\mathrm{Pt}[12-14]$, $\mathrm{Pt}$ single crystals[15], and electrochemically faceted $\mathrm{Pt}$ electrodes[16]. The present paper describes the behaviour of the $\mathrm{Ag} / \mathrm{Ag}^{+}$electrode reactions on EDPtEs of different roughness with the following main purposes: (i) to establish the voltammetric conditions for $\mathrm{Ag}$ upd and $\mathrm{Ag}$ opd on this type of electrode; (ii) to determine the influence of the applied potential routine on the electrochemical reaction, particularly concerning the non-uniform accessibility of the rough metal surface; (iii) to establish whether under certain conditions the voids of the columnar structure could approach the voltammetric behaviour of a thin layer cell electrode for the $\mathbf{A g} / \mathrm{Ag}^{+}$electrode reactions. The latter opens the possibility of new electrode designs for trace electroanalysis by combining the advantages of a large electrode surface area and those of thin layer voltammetry.

\section{EXPERIMENTAL}

The starting working electrode material was a polycrystalline (pc) platinum wire $(99.99 \%$ purity, $0.05 \mathrm{~cm}^{2}$ geometric area) encased in a glass holder. The electrochemical cell was completed with a platinum counter electrode $\left(4 \mathrm{~cm}^{2}\right.$ apparent area). A reversible hydrogen electrode (rhe) in the same electrolyte solution was used as reference. Two electrolyte solutions were used, namely $1 \mathrm{M}$ $\mathrm{H}_{2} \mathrm{SO}_{4}+5 \times 10^{-4} \mathrm{M} \mathrm{Ag}_{2} \mathrm{SO}_{4}$ and $1 \mathrm{M} \mathrm{H}_{2} \mathrm{SO}_{4}$, the latter being employed for blank experiments. On the basis of previously reported data, the chosen $\mathrm{Ag}_{2} \mathrm{SO}_{4}$ concentration was considered as the most appropriate for the present purpose[13]. Solutions were prepared from p.a. quality chemicals and Milli-Q* water. Runs were made at $25^{\circ} \mathrm{C}$ under nitrogen saturation.

The EDPtEs were made in $1 \mathrm{M} \mathrm{H}_{2} \mathrm{SO}_{4}$ by using a technique described elsewhere[1-3]. It consisted of two stages, the first implying the accumulation of a hydrous platinum oxide layer (HPtOL) on the starting pc Pt electrode, and the second the electroreduction of the HPtOL to produce the EDPtE. The first stage proceeds through the application of a square wave potential routine at $4 \mathrm{kHz}$ between 0.05 and $1.4 \mathrm{~V}(v s$ rhe) for a time $(t a)$ between $30 \mathrm{~s}$ and 3 min depending on the preset roughness factor $(R)$ value. The second stage was the potentiodynamic electroreduction of HPtOL at $0.001 \mathrm{~V} \mathrm{~s}^{-1}$. In this way values of $R$ ranging betwen 10 and 100 could be obtained. 
The value of $R$ was defined as the $\left(Q_{\mathrm{H}}\right) /\left(Q_{\mathrm{Hi}}\right)$ ratio, where $\left(Q_{\mathrm{H}}\right)$ and $\left(Q_{\mathrm{Hi}}\right)$ are the $\mathrm{H}$-adatom electrodesorption voltammetric charge for the EDPtE and that for the starting Pt electrode, respectively, both charges being measured in $1 \mathrm{M} \mathrm{H}_{2} \mathrm{SO}_{4}$ under the same voltammetric conditions. Similar values of $R$ were obtained by using the corresponding $\mathrm{O}$-adatom electrodesorption charge, at least when voltammetry was run at $0.1 \mathrm{~V} \mathrm{~s}^{-1}$ between 0.05 and $1.45 \mathrm{~V}$. As recently prepared EDPtEs exhibit a slow roughness decay[8], they were first stored in $1 \mathrm{M} \mathrm{H}_{2} \mathrm{SO}_{4}$ under open circuit, and later employed in the experiments when the change in the value of $R$ was smaller than $1 \%$ in $24 \mathrm{~h}$. Nevertheless, the value of $R$ was systematically checked before and after each run.

The $\mathrm{Ag} / \mathrm{Ag}^{+}$electrode reactions on the EDPtE were studied under different potential routines by changing systematically the operating conditions, as is usually done in potential controlled electrochemical measurements.

\section{RESULTS}

\section{Reference voltammetry data on bright pc $\mathrm{Pt}$ electrodes}

The voltammograms run with pc platinum in $1 \mathrm{M}$ $\mathrm{H}_{2} \mathrm{SO}_{4}+5 \times 10^{-4} \mathrm{M} \mathrm{Ag}_{2} \mathrm{SO}_{4}$ at $0.02 \mathrm{~V} \mathrm{~s}^{-1}$ from 0.05 to $1.45 \mathrm{~V}$ by either increasing or decreasing stepwise the cathodic switching potentials (Fig la and b) show in the negative potential going scan the appearance of peaks Ic and IIc as well as a cathodic limiting current extending from $c a 0.4 \mathrm{~V}$ downwards. The latter can also be observed in the reverse potential scan, and in this case it is followed by two largely overlapping anodic current peaks (IIIa and IIa), and at high positive potentials by the anodic peak Ia. The display of the different contributions can be better observed as the cathodic switching potential is set increasingly negative, as the relative contributions of peaks IIIa and IIa become sensitive to the preset calhodic switching potential.

The voltammetric results are consistent with the appearance of at least two conjugated redox systems, namely the pair of peaks Ic/Ia which corresponds to the overlapping O-electrosorption and Ag upd/stripping processes, and the pair of peaks IIc/IIa related to bulk Ag electrodeposition/electrodissolution. On the other hand, peak IIIa can be assigned to the anodic stripping of the second silver layer. In these experiments one can also note that the $\mathrm{H}$-adatom electrosorption processes which are well known at bright pc Pt electrodes, are inhibited. Moreover, in the $\mathrm{Ag}^{+}$-ion containing solution, the initiation of the O-electroadsorption is positively shifted (Fig. 2a). It should also be noted that the potential regions of $\mathrm{Ag}$ upd and $\mathrm{Ag}$ opd which are determined by $E r$, the reversible potential of the $\mathrm{Ag} /\left(1 \times 10^{-3} \mathrm{M} \mathrm{Ag}^{+}\right), E r=0.62 \mathrm{~V}$, cannot be clearly established. Furthermore, there is a competition between the $\mathrm{Ag}$ upd stripping and the O-atom electroadsorption which can be easily concluded by comparing the voltammograms shown in Figs 1 and 2 with that of the blank.

When the cathodic and anodic switching potentials are set at 0.59 and $1.12 \mathrm{~V}$, respectively, the early stages for both $\mathrm{Ag}$ upd and $\mathrm{O}$-atom electroadsorption can be more clearly displayed (Fig. 2b); but when those switching potentials are set at 0.49 and $0.99 \mathrm{~V}$, respectively, only the conjugated pair of peaks IIa/IIc can be observed. These peaks are accompanied by a minor contribution of those related to the O-electrosorption processes.

\section{Voltammetry data obtained on the EDPtE}

In general, the voltammograms run with EDPtEs in $1 \mathrm{M} \mathrm{H}_{2} \mathrm{SO}_{4}+5 \times 10^{-4} \mathrm{M} \mathrm{Ag}_{2} \mathrm{SO}_{4}$ (Fig. 3) are considerably different from those shown in Figs 1 and

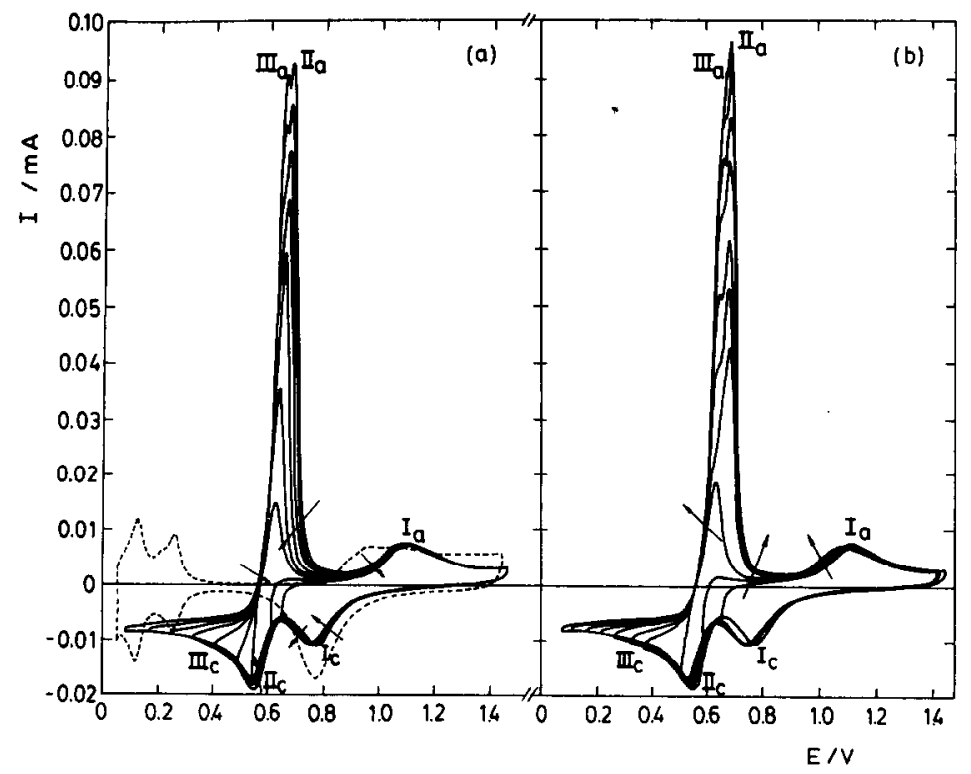

Fig. 1. Cyclovoltammograms obtained on bright $\mathrm{Pt}$ (pc) in $1 \mathrm{M}_{2} \mathrm{H}_{2} \mathrm{SO}_{4}(---)$, and in $1 \mathrm{M}$ $\mathrm{H}_{2} \mathrm{SO}_{4}+5 \times 10^{-4} \mathrm{M} \mathrm{Ag}_{2} \mathrm{SO}_{4}(\longrightarrow)$. Cathodic switching potential either decreased (a) or increased (b) stepwise, $v=0.02 \mathrm{~V} \mathrm{~s}^{-1} ; 25^{\circ} \mathrm{C}$. 


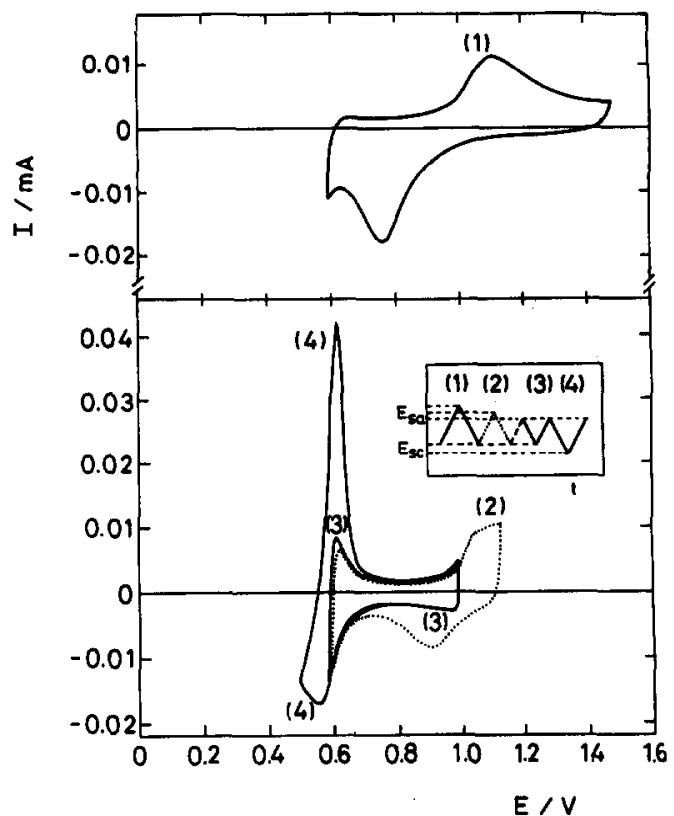

Fig. 2. Cyclovoltammograms obtained on bright $\mathrm{Pt}(\mathrm{pc})$ in $1 \mathrm{M} \mathrm{H}_{2} \mathrm{SO}_{4}+5 \times 10^{-4} \mathrm{M} \mathrm{Ag}_{2} \mathrm{SO}_{4}$ at $v=0.02 \mathrm{~V} \mathrm{~s}^{-1}$ $25^{\circ} \mathrm{C}$, by changing the potential limits in the subsequent potential cycles as indicated by the numbers and traces in both the potential routine (inset) and the voltammograms. (1) $E_{\mathrm{s}, \mathrm{c}}=0.59 \mathrm{~V}$ and $E_{\mathrm{s}, \mathrm{a}}=1.47 \mathrm{~V} ;$ (2) $E_{\mathrm{s}, \mathrm{c}}=0.59 \mathrm{~V}$ and $E_{\mathrm{s}, \mathrm{a}}=1.12 \mathrm{~V}$; (3) $E_{\mathrm{s}, \mathrm{a}}=0.99 \mathrm{~V}$ and $E_{\mathrm{s}, \mathrm{c}}=0.59 \mathrm{~V}$; (4) $E_{\mathrm{s}, \mathrm{a}}=0.99 \mathrm{~V}$ and $E_{\mathrm{s}, \mathrm{c}}=0.49 \mathrm{~V}$.

2 for $\mathrm{pc} \mathrm{Pt}$ electrodes under the same operating conditions. Furthermore, this difference strongly depends on the value of $R$ (Fig. $3 \mathrm{a}-\mathrm{c}$ ). The corresponding voltammograms for all the values of $R$ show that peak IIc appears only as a shoulder for relatively large values of $R(R=10$ and $R=40)$, in contrast to the well-defined conjugated pair of peaks IIa/IIc. Furthermore, for $R=70$, the pair of peaks IIc/IIa is no longer observed (Fig. 3c). Otherwise, the contribution of peaks Ia and Ic becomes better defined as $\boldsymbol{R}$ increases. Furthermore, the EDPtEs show a partial and selective inhibition of the $\mathrm{H}$-adatom electrosorption reactions, together with a shift of the entire voltammogram downwards due to the $\mathrm{Ag}$ electrodeposition reaction. Both effects, however, tend to disappear very rapidly as $\boldsymbol{R}$ increases, the voltammograms approaching that of the blank.

The electroreduction voltammograms indicate that once bare $\mathrm{Pt}$ sites become available at the electrode surface, Ag upd electrodeposition begins to take place. Then, the voltammetric response of the system suggests that a portion of the Pt surface becomes covered by a more or less uniform $\mathrm{Ag}$ layer. The remaining bare $\mathrm{Pt}$ surface in contact with the $\mathrm{Ag}^{+}$ion-free acid solution becomes responsible for the appearance of the $\mathrm{H}$-adatom electrosorption peaks.

The precedent results suggest the convenience of running an experiment with an EDPtE consisting of a potential cycling as earlier indicated in $1 \mathrm{M}$ $\mathrm{H}_{2} \mathrm{SO}_{4}+5 \times 10^{-4} \mathrm{M} \mathrm{Ag} \mathrm{AO}_{4}$ and leaving the electrode $24 \mathrm{~h}$, immersed in the electrolyte solution under open circuit conditions. Afterwards, the voltammetric behaviour of the EDPtE corresponds to that of the

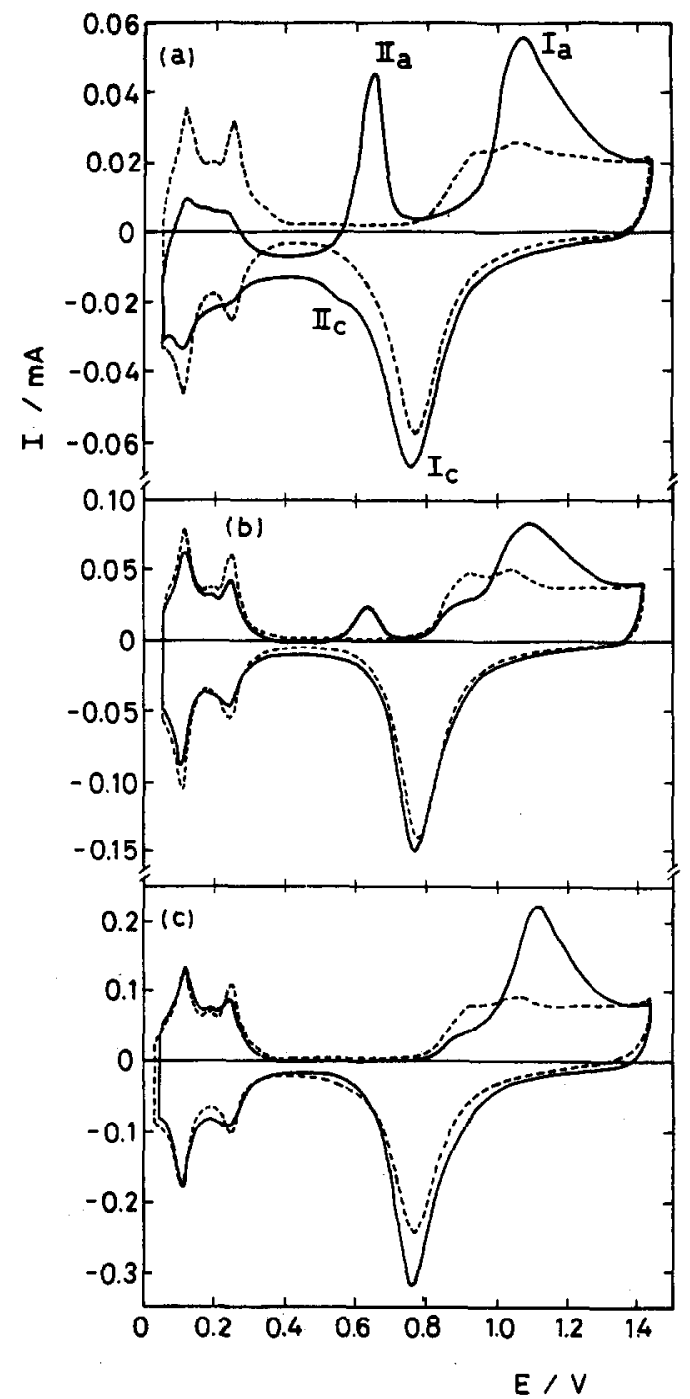

Fig. 3. Cyclovoltammograms obtained with EDPtE in $1 \mathrm{M}$ $\mathrm{H}_{2} \mathrm{SO}_{4}+5 \times 10^{-4} \mathrm{M} \mathrm{Ag}_{2} \mathrm{SO}_{4}(-)$ and in $1 \mathrm{M} \mathrm{H}_{2} \mathrm{SO}_{4}$ (-) at $0.02 \mathrm{~V} \mathrm{~s}^{-1}, 25^{\circ} \mathrm{C}$. (a) $R=10$; (b) $R=40$; (c) $R=70$.

reversible $\mathrm{Ag} / \mathrm{Ag}^{+}$electrode reactions occurring at a large area $\mathbf{A g}$ electrode. In this case the $\mathbf{A g}$ plating depends on the immersion time in the $\mathrm{Ag}^{+}$-ion-containing solution which is required for the porous structure to be completely filled with $\mathrm{Ag}^{+}$-ions from the solution. This immersion time increases according to the value of $\boldsymbol{R}$. Correspondingly, the open circuit potential becomes very close to the $E r$ value. Under these circumstances, the cyclovoltammogram resulting for the $\mathrm{Ag}$ plated EDPtE presents the typical voltammogram of the $\mathrm{Ag} / \mathrm{Ag}^{+}$-ion electrode processes in a thin layer electrocinemical cell (Fig. 4a). However, one can observe that the heights of the anodic and cathodic current peaks in the cyclovoltammograms decrease gradually along cycling approaching the features already described for the EDPtE substrate (Fig. 4b). In this case, the number of cycles required to approach the initial voltammogram increases with both the value of $R$ and the EDPtE immersion time into the $\mathrm{Ag}^{+}$-ion-containing solution under open circuit conditions. A similar 


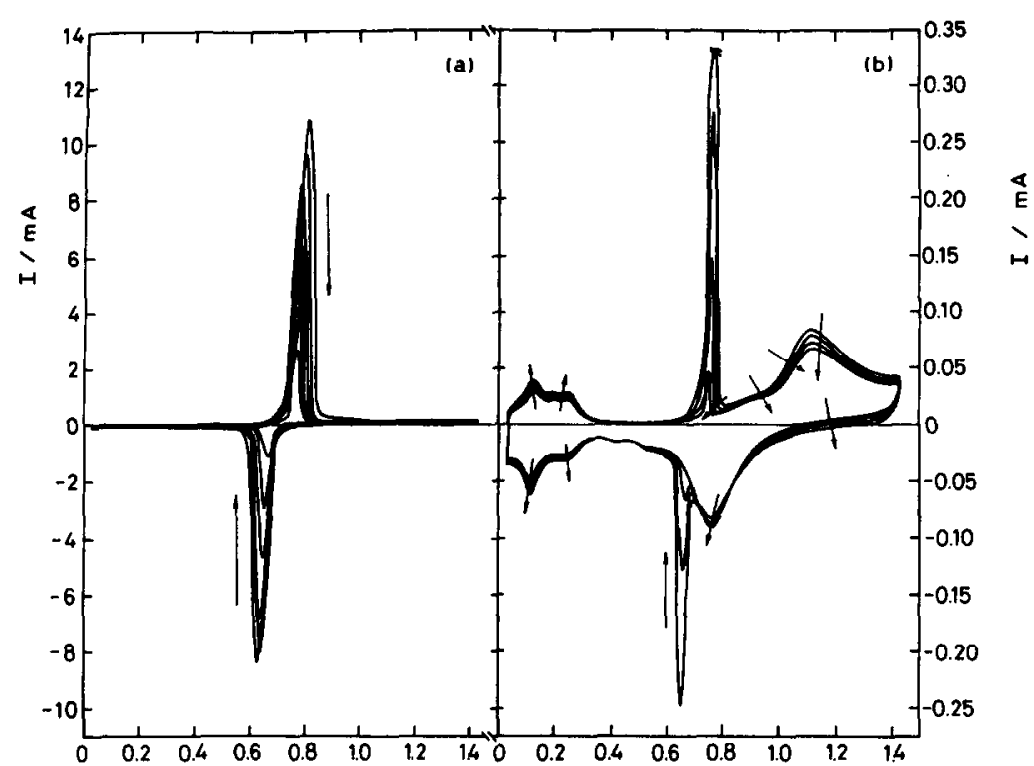

Fig. 4. Cyclovoltammograms obtained with $\operatorname{EDPtE}(R=40)$ in $1 \mathrm{M} \mathrm{H}_{2} \mathrm{SO}_{4}$ at $0.02 \mathrm{~V} \mathrm{~s}^{-1}, 25^{\circ} \mathrm{C}$. The electrode has been previously potential cycled and then left during $24 \mathrm{~h}$ in the $\mathrm{Ag}^{+}$-ion containing solution at open circuit.

voltammetric response can also be obtained when the Ag plated EDPtE is cycled in plain $1 \mathrm{M} \mathrm{H}_{2} \mathrm{SO}_{4}$. The latter experiment also provides quantitative information about the amount of $\mathrm{Ag}$ deposited under open circuit conditions.

3. The influence of potential scan rate on the voltammetric response of the $\mathrm{Ag} / \mathrm{Ag}^{+}$electrode processes on EDPtE

Further details of the $\mathrm{Ag} / \mathrm{Ag}^{+}$-ion electrode processes in $1 \mathrm{M} \mathrm{H}_{2} \mathrm{SO}_{4}$ on EDPtE, particularly in relation to the EDPtE structure, can be derived from the voltammograms (Fig. 5) recorded in the $\mathrm{Ag}^{+}$-ioncontaining solution at $0.001 \mathrm{~V} \mathrm{~s}^{-1}<v<0.2 \mathrm{~V} \mathrm{~s}^{-1}$ by changing $R$ from 10 to 70 . These results show that for very low values of $v$ (Fig. 5a) the $\mathrm{H}$-electrosorption processes are already largely inhibited, whereas the $\mathrm{Ag} / \mathrm{Ag}^{+}$-ion electrode processes are considerably enhanced (peaks $\mathrm{IIa} / \mathrm{IIc}$ ). In this case the $\mathrm{Ag}$ electrodeposition limiting current can be clearly observed, and the first $\mathrm{O}$-electroadsorption stage (peak $I^{\prime} a$ ) is appreciably diminished. Otherwise, those voltammograms obtained in the $0.01 \mathrm{~V} \mathrm{~s}^{-1}<v<0.2 \mathrm{~V} \mathrm{~s}^{-1}$ range (Fig. $5 b$ and $c$ ), exhibit a clearer definition of those peaks related to the $\mathrm{H}$-electrosorption processes as $v$ increases. The same trend is observed for the $\mathrm{O}$-electrosorption peaks, although in this case the contribution of the $\mathrm{Ag} / \mathrm{Ag}^{+}$-ion electrode processes are strongly diminished.

\section{DISCUSSION}

The present results demonstrate the influence of the roughness substrate characteristics on the complex processes taking place on both the upd and opd metal layer formation, particularly when the experiments are made at relatively high potential sweep rates. In the present case, new processes coupled to the proper
$\mathrm{Ag} / \mathrm{Ag}^{+}$electrode reactions can be distinguished by using adequate values of $R$ and voltammetry conditions.

\section{Early stages of $\mathrm{Ag}$ electrodeposition and O-mono- layer electroreduction}

The conjugated overall reactions related to peaks Ic/Ia can be expressed by the following equation in both directions, respectively[12-16]:

$$
\mathrm{Pt}(\mathrm{O})+\mathrm{Ag}^{+}+2 \mathrm{H}^{+}+3 \mathrm{e}^{-}=\mathrm{H}_{2} \mathrm{O}+\mathrm{Pt}(\mathrm{Ag}),
$$

where the parentheses denote surface species at the $\mathrm{Pt}$ substrate. Reaction (1) in the forward direction corresponds to the formation of the first monolayer of $\mathrm{Ag}$ upd competing with the $\mathrm{O}$-adatom electrodesorption.

On the other hand, peak IIc corresponds to a complex peak involving the nucleation and growth of a second $\mathrm{Ag}$ layer at $\mathrm{Er}$, and bulk $\mathrm{Ag}$ electrodeposition, both processes undergoing under-diffusion control[13,16,17]. These two processes are mainly concerned with $\mathrm{Ag}-\mathrm{Ag}$ interactions, in contrast to those described by reaction (1) which comprises principally $\mathrm{Ag}-\mathrm{Pt}$ and $\mathrm{Pt}-\mathrm{O}$ interactions. During the positive potential going scan, bulk Ag and the second $\mathrm{Ag}$ layer are simultaneously electrodissolved in the potential range of peaks IIIa-IIa.

\section{Silver layer growth modes}

A close inspection of the results shown in Fig. 3, run at a relatively high potential sweep rate, indicates that the total Ag electrodeposited charge on the different EDPtEs increases with $R$ although the corresponding charge density referred to the real active surface area of the substrate decreases as $R$ increases. Correspondingly, one can observe that the contribution of both bulk $\mathrm{Ag}$ and sccond $\mathrm{Ag}$ layer growth decreases as $R$ increases, in contrast to the contribution of the $\mathbf{A g}$ monolayer which remains practically independent of the $R$ value. This means that in 




Fig. 5. Cyclovoltammograms obtained with EDPtE $(R=40)$ in $1 \mathrm{M} \mathrm{H}_{2} \mathrm{SO}_{4}+5 \times 10^{-4} \mathrm{M} \mathrm{Ag}_{2} \mathrm{SO}_{4}$ at different

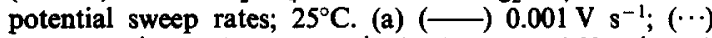
$0.005 \mathrm{~V} \mathrm{~s}^{-1}$; (--) $0.01 \mathrm{~V} \mathrm{~s}^{-1}$. (b) (-) $0.02 \mathrm{~V} \mathrm{~s}^{-1} ;(\cdots)$ $0.05 \mathrm{~V} \mathrm{~s}^{-1}$. (c) (一) $0.1 \mathrm{~V} \mathrm{~s}^{-1} ;(\cdots) 0.2 \mathrm{~V} \mathrm{~s}^{-1}$.

this case the relative number of $\mathbf{A g}-\mathbf{A g}$ and $\mathbf{A g}-\mathrm{Pt}$ bonds contributing to the Ag layer growth depend on $R$. Then, the ratio between the total amount of electrodeposited $\mathrm{Ag}$ (second $\mathrm{Ag}$ plus bulk $\mathrm{Ag}$ ) and that of the $\mathrm{Ag}$ monolayer on the $\mathrm{Pt}$ substrate decreases as $R$ changes from 10 to 70 . This fact cannot be exclusively explained in terms of the columnat microstructure of the EDPtE as in this case one would expect that Ag electrodeposition would occur preferentially at tip sites of the columns, the voids between columns remaining as Ag-free sites which are active for either $\mathrm{H}$ - or O-electrosorption. These considerations would imply that the effective substrate area for $\mathrm{Ag}$ electrodeposition at high potential sweep rates, would not differ markedly as $R$ increases.

For the diffusion controlled $\mathrm{Ag}^{+}$ion electrodeposition under high potential sweep rate, the overlapping of the radial diffusion fields at the tips would result in a linear monodirectional diffusion field so that only the outer surface of the rough substrate would act as a collecting plane for the arriving $\mathbf{A g}^{+}$ ions, so there would be no reason for expecting a complete inhibition of second layer and bulk $\mathrm{Ag}$ electrodeposition. However, $\mathrm{Ag}$ electrodeposition on the tip domains of the columnar microstructure generates at least two concentration gradients for $\mathbf{A g}$ atoms, one between the tip domain and the wall and the bottom of the intercolumnar voids, and another between the growing Ag centres and the bulk substrate. In this respect, it should be noted that $\mathrm{Ag}$ atoms exhibit a greater surface mobility than $\mathrm{Pt}$ atoms at room temperature[18]. Considering that the $\mathrm{Ag}-\mathrm{Pt}$ bond is stronger than the $\mathbf{A g}-\mathbf{A g}$ bond, the arriving $\mathrm{Ag}^{+}$ions contacting $\mathbf{P t}$ sites should be more probably attached to those sites, whereas those ones sticking to Ag-covered domains can diffuse a relatively large distance to reach a free $\mathrm{Pt}$ site for final attachment. This fact results in a net flux of $\mathrm{Ag}$ atoms from tips to valleys of the porous structure to produce a $\mathrm{Ag}$ layer more uniformly distributed on the Pt substrate. Consequently, the early stage of bulk $\mathrm{Ag}$ electrodeposition should be to some extent hindered, and the growth of Ag centres on EDPtEs should be envisaged as a transient process whose half-life time is shorter than the half-life time of mass transport processes at the surface. The abovedescribed processes can be described as a 3-D to 2-D rearrangement provided that free $\mathrm{Pt}$ sites become available.

Another interesting facet of these results (Fig. 3) is that the contribution of the H-electrosorption processes increase as $R$ increases reaching for $R=70$ a value very close to that of the blank without observing the corresponding reduction of the $\mathrm{Ag}$ electrodeposit at the monolayer level. Thus, one should consider two additional processes, namely the possible penetration of $\mathrm{Ag}$ atoms underneath coupled to the displacement of Pt atoms on the substrate surface to allow bulk diffusion of $\mathrm{Ag}$ atoms. This implies that $\mathrm{Ag}$ atoms have two options, either to diffuse on the Ag surface layer or to diffuse into bulk $\mathrm{Pt}$ to form a sort of alloy skin. As a matter of fact, it was reported that the stripping of $\mathrm{Ag}$ from a $\mathrm{Pt}$ electrode when a $\mathrm{Ag}-\mathrm{Pt}$ alloy has formed, takes place at $1.2 \mathrm{~V}$, just in the potential range of peak Ia where the $\mathbf{A g}$ monolayer is also anodically stripped[13, 14].

The Ag-Pt alloying competes with the Ag layer growth. Accordingly, bulk Ag formation would be hindered if either $\mathrm{Pt}$ free sites are available or Ag-adatoms have enough time to diffuse into $\mathrm{Pt}$. Both processes produce a dilution of $\mathrm{Ag}$-adatoms either by the excess of surface present in the columnar microstructure (free $\mathrm{Pt}$ sites) or by moving $\mathrm{Ag}$ adatoms into bulk Pt. For EDPtE the nucleation and growth of bulk $\mathrm{Ag}$ requires more time (charge) than on a conventional smooth substrate.

\section{The $\mathrm{Ag}^{+}-\mathrm{H}$ atom displacement reaction and the $\mathrm{Ag} / \mathrm{Ag}^{+}$electrode reaction at pores}

The voltammetric features obtained on the EDPtEs can be reasonably explained on the basis of the precedent analysis. At low $v$, all the columnar structure becomes Ag plated as there is enough time for $\mathrm{Ag}^{+}$-ions to diffuse from the bulk of the solution to the voids of the columnar structure. Conversely, at high $v$, there is only a relatively small amount of 
Ag deposited compared with the large number of free $\mathrm{Pt}$ sites available. Hence, the accessibility of the electrode surface to the reacting species is greatly limited. This fact can be unambiguously demonstrated through the spontaneous $\mathrm{Ag}$ plating of the previously $\mathrm{H}$-atom-covered EDPtE surface at open circuit. This process can be associated with the displacement of $\mathrm{H}$ atoms by $\mathrm{Ag}^{+}$ions at the porous $\mathrm{Pt}$ structure, according to a reaction such as:

$$
\mathrm{Pt}(\mathrm{H})+\mathrm{Ag}^{+}=(\mathrm{Ag}) \mathrm{Pt}+\mathrm{H}^{+} \text {. }
$$

Reaction (2) under the present conditions is thermodynamically feasible. Accordingly, when the porous structure is filled with $\mathrm{Ag}^{+}$ion-containing solution, the reaction at pores during potential cycling (Fig. 4) is:

$$
\text { (Ag)Pt }=\mathrm{Ag}^{+} \text {(sol.pores) }=\mathrm{Ag}^{+} \text {(sol.bulk). }
$$

The voltammetric characteristics of reaction (3) at pores approaches very closely those reported for the same reaction in thin cell voltammetry[19].

\section{CONCLUSIONS}

The precedent results point out that there are two limiting cases for the voltammetric behaviour of $\mathrm{Ag} / \mathrm{Ag}^{+}$-ion electrode reactions on EDPtE. The first corresponds to that of a very low potential scan rate in which the voltammograms approach that obtained for bright pc $\mathrm{Pt}$. In this case, $\mathrm{Ag}^{+}$-ions have a sufficiently long diffusion length to be deposited on the entire rough Pt surface, leaving only a few surface sites free for either $\mathrm{H}$ - or O-atom electrosorption. Another limiting case appears at high scan rates where the behaviour is totally opposed to that previously described. In fact, $\mathrm{Ag}^{+}$-ions are then deposited only on those sites which become easily accessible (tip domains), while $\mathrm{H}$ - and O-atoms occupy $\mathrm{Ag}$-free $\mathrm{Pt}$ sites (wall and bottom domains). Hence, the voltammograms approach that of the blank. Under these conditions the 3-D to 2-D Ag layer rearrangement can be concluded.

A similar behaviour can be observed for EDPtEs at a constant $v$ and variable $R$. At low values of $R$ the voltammetric features become similar to those found at low $v$ values, whereas for high $R$ values results are comparable with those obtained at high $v$ values.
Acknowledgements-Authors thank the Consejo Nacional de Investigacions Cientificas y Técnicas of Argentina, and the Comisión de Investigaciones Científicas y Técnicas de la Provincia de Buenos Aires for financial support.

\section{REFERENCES}

1. A. Chialvo, W. E. Triaca and A. J. Arvia, J. electroanal. Chem. 171, 303 (1984).

2. A. Visintin, W. E. Triaca and A. J. Arvia, J. electroanal. Chem. 284, 465 (1990).

3. A. J. Arvia, R. C. Salvarezza and W. E. Triaca, Electrochim. Acta 34, 1057 (1989).

4. R. O. Lezna, N. R. de Tacconi, C. L. Perdriel and A. J. Arvia, Proc. Symp. Electrochem. Soc. on Electrode Materials (Edited by S. Srinivasan, S. Wagner and $\mathrm{H}$. Wroblowa), Vol. 87-12, p. 31. The Electrochemical Society, Pennington, N.J. (1987).

5. J. Zerbino, C. L. Perdriel and A. J. Arvia, Electrochim. Acta, submitted.

6. M. Gómez, R. C. Salvarezza, J. M. Vara and A. J. Arvia, submitted.

7. L. Vázquez, J. Gómez, A. M. Baró, N. García, M. L. Marcos, J. González Velasco, J. M. Vara, A. J. Arvia, J. Presas, A. García and M. Aguilar, J. Am. chem. Soc. 109,1730 (1987).

8. L. Vázquez, A. Bartolomé, A. M. Baró, C. Alonso, R. C. Salvarezza and A. J. Arvia, Surf. Sci. 215, 171 (1989); C. Alonso, R. C. Salvarezza, J. M. Vara, A. J. Arvia, L. Vázquez, A. Bartolomé and A. M. Baró, J. electrochem. Soc. 137, 2161 (1990).

9. D. J. Srolovitz, A. Mazor and B. G. Bukiet, J. Vac. Sci. Technol. A6, 2371 (1988).

10. M. L. Marcos, J. M. Vara, J. González Velasco and A. J. Arvia, J. electroanal. Chem. 224, 189 (1987).

11. A. M. Castro Luna, M. C. Giordano and A. J. Arvia, J. electroanal. Chem. 198, 137 (1986).

12. T. Chirchie, C. Mayer, K. Juttner and W. J. Lorenz, J. electroanal. Chem. 191, 405 (1985).

13. R. C. Salvarezza, D. V. Vasquez Moll, M. C. Giordano and A. J. Arvia, J. electroanal. Chem. 213, 301 (1986).

14. D. Alonzo and B. Scharifker, J. electroanal. Chem. 274, 167 (1989).

15. El Omar, R. Durand and R. Faure, J. electroanal. Chem. 160, 385 (1984).

16. B. Parajón, J. Canullo, D. V. Vasquez Moll, R. C. Salvarezza, M. C. Giordano and A. J. Arvia, J. electroanal. Chem. 244, 261 (1988).

17. A. Milchev, T. Chirchie, K. Juttner and W. J. Lorenz, Electrochim. Acta 32, 1039 (1987); 32, 1043 (1987).

18. G. K. Gimzewski and H. Humbert, IBM Jl Res. Dev. 30, 472 (1986).

19. A. T. Hubbard and F. C. Anson, Electrounalytical Chemistry (Edited by A. J. Bard), Vol.4, p. 129. M. Dekker, New York (1970). 